\title{
Uma Revisão sobre Sistemas de Referenciamento Linear para Cadastro Rodoviário e seu Potencial de Aplicação no Estado do Rio Grande do Sul (Brasil)
}

\author{
A Review on Linear Referencing Systems for Road Registry and its \\ Application Potential in the State of Rio Grande do Sul (Brazil) \\ Aline Gomes da Silva Druzina ${ }^{1}$ \\ Sérgio Florêncio de Souza ${ }^{2}$ \\ Felipe Geremia Nievinski ${ }^{3}$
}

Recebido em novembro de 2018. Aprovado em setembro de 2019.

\begin{abstract}
RESUMO
No setor rodoviário, a atividade de cadastro e integração das informações é tarefa contínua, podendo ser realizada com a utilização de Sistemas de Referenciamento Linear (SRL) e/ou de Sistemas de Informações Geográficas (SIG). Os SRL são baseados na determinação unidimensional de um ponto desconhecido considerando uma referência, direção e distância conhecidas. Os SIG são baseados em geometrias bidimensionais e apresentam conceitos, algoritmos e modelos de dados próprios, sendo ferramentas indispensáveis no desenvolvimento dos processos de transportes. SRL e SIG são complementares tendo suas vantagens e desvantagens particulares. O desafio por décadas tem sido desenvolver práticas e modelos de dados genéricos para SRL que sejam adaptáveis, flexíveis e personalizáveis para atender a diferentes ambientes. Infelizmente, não há um consenso com relação à metodologia e padrões a serem seguidos para a integração das informações rodoviárias no Brasil. Por exemplo, muitos aspectos das normativas vigentes no âmbito da Comissão Nacional de Cartografia são diferentes das adotadas pelo Departamento Nacional de Infraestrutura de Transportes. Nos EUA, diversas modelagens conceituais de dados foram propostas ao longo dos anos, comprovando uma preocupação constante na padronização e integração das informações rodoviárias. Internacionalmente, foi desenvolvida a norma ISO 19148 para SRL. Diante deste cenário e da ausência de normativas e especificações no Brasil para SRL, o presente artigo apresenta uma revisão a respeito das principais definições e modelos de dados para SRL existentes que possam ser aplicados ao sistema rodoviário. Diversos aspectos da normativa internacional são discutidos, como por exemplo métodos (absoluto - quilometragem, milhagem, etc. -, relativo, interpolativo) e elementos (curva, feição, aresta direcionada) para SRL. Um estudo de caso preliminar no âmbito do
\end{abstract}

1UFRGS. Programa de Pós-Graduação em Sensoriamento Remoto. E-mail: aline.druzina@gmail.com ${ }^{2}$ UFRGS. Programa de Pós-Graduação em Sensoriamento Remoto. E-mail: sergio.florencio@ufrgs.br 3UFRGS. Programa de Pós-Graduação em Sensoriamento Remoto. E-mail: felipe.nievinski@ufrgs.br 
Departamento Autônomo de Estradas de Rodagem do estado do Rio Grande do Sul também é descrito.

PALAVRAS-CHAVE: SIG. SRL. Cadastro. Rodovias. Transporte.

\begin{abstract}
In the transportation sector, the task of registering and integrating information is a continuous task and can be performed using Linear Referencing Systems (LRS) and/or Geographic Information Systems (GIS). LRS are based on one-dimensional determination of an unknown point considering a known reference, direction and distance. GIS are based on two-dimensional geometries and have unique concepts, algorithms and data models, and are indispensable tools in the development of transport processes. LRS and GIS are complementary with their own advantages and disadvantages. The challenge for decades has been to develop practices and generic data models for LRS that are adaptable, flexible and customizable to suit different environments. Unfortunately, there is no consensus on the methodology and standards to be adopted for the integration of road information in Brazil. Many aspects of the regulations in force within the National Cartography Commission are different from those adopted by the National Department of Transport Infrastructure. In the USA, several conceptual data models have been proposed over the years, proving a constant concern for the standardization and integration of road information. Internationally, the ISO 19148 standard was developed for LRS. In view of this scenario and the absence of regulations and specifications in Brazil for LRS, this article provides a review of the main definitions and data models for LRSs that can be applied to the road system. Several aspects of the international standard are discussed, such as methods (absolute - kilometrage, mileage, etc. -, relative, interpolative) and elements (curve, feature, directed edge) for LRS. A preliminary case study within the Autonomous Department of Highways in the state of Rio Grande do Sul is also described.
\end{abstract}

KEYWORDS: GIS. LRS. Registry. Highways. Transportation.

$$
* * *
$$

\title{
1 Introdução
}

A partir do desenvolvimento das geotecnologias, a atividade de localização espacial das informações de transportes se tornou tarefa mais simples. Por exemplo, com o uso de um aparelho de celular equipado com GPS (Global Positioning System - Sistema de Posicionamento Global), qualquer pessoa, não necessariamente especialista na área, consegue obter coordenadas em tempo real da sua posição. Neste contexto, a quantidade de informações geoespaciais coletadas, processadas e armazenadas pela 
humanidade contribui para que muitos objetos e eventos de transportes possam ser registrados e relacionados a algum lugar na Terra (FEKPE et al., 2003; DEMIREL, 2002).

O impacto desta evolução na geolocalização das informações de transportes vem provocando uma série de revisões e mudanças nos procedimentos adotados para gerenciamento, monitoramento e manutenção dos dados de infraestrutura de transportes. A tomada de decisão por parte dos órgãos governamentais de transportes a respeito de onde e como será realizado o investimento acaba por ser fortemente dependente das informações geoespaciais que descrevem as instalações existentes e seu estado de conservação (FHWA, 2014b; BUTLER, 2008a).

No setor rodoviário, a grande maioria das informações apresentam características espaciais multidimensionais, podendo ser estáticas ou dinâmicas. A atividade de integração destas informações rodoviárias é tarefa contínua, que atualmente vem sendo realizada pela maioria dos Departamentos de Transportes e Agências de Transportes - estaduais, nacionais e internacionais - com a utilização de Sistemas de Referenciamento Linear (SRL) e/ou de Sistemas de Informações Geográficas aplicados a Transportes (SIG-T). Há, porém, uma diferença marcante na dimensionalidade da localização geográfica registrada nesses dois sistemas.

Os SRL são utilizados para descrever e localizar objetos ao longo das rotas dos modais de transportes muito antes do uso de tecnologias de SIG e da existência de computadores, tendo sua origem nos primórdios da civilização (BARNARD, 2008; PAULSON, 2005). Este sistema está baseado na determinação linear ou unidimensional de um ponto de interesse com relação a um ponto de referência, seguindo uma direção e distância conhecidas ao longo de uma dada via (DEMIREL, 2002).

A partir do século XX, os SIG-T, que apresentam conceitos, algoritmos e modelos de dados próprios, tornaram-se ferramentas indispensáveis no planejamento de transportes. Em SIG-T as vias são definidas usando principalmente sistemas de referência bidimensionais. O cadastro dos 
atributos da via é realizado através da segmentação, de acordo com a mudança de características (estado de conservação, tipo de pavimento, velocidade máxima, etc.). Já os eventos, tais como acidentes de trânsito, deslizamentos de taludes, etc., são armazenados como dados pontuais em separado. No entanto, devido à quantidade e variabilidade das informações associadas à via, a segmentação comum não é um recurso prático e versátil para cadastros mais complexos, como quando trabalhando com muitos atributos como os exemplos acima, cuja interseção resultaria em segmentos pequenos e numerosos (FHWA, 2014b; DEMIREL, 2002).

É importante distinguir o cadastro rodoviário (road registry, em inglês) do cadastro territorial ou cadastro imobiliário (cadastre, em inglês) (LOCH, 2007). Esse tem como unidade básica a parcela, que é uma região com propriedades jurídicas uniformes; já aquele, tem como primitiva o eixo da rodovia, ou seja, uma feição linear.

Não existe até o presente momento um padrão nacional com relação à metodologia para a integração das informações rodoviárias georreferenciadas. Muitos aspectos das normativas vigentes no âmbito da Comissão Nacional de Cartografia (CONCAR) são diferentes das adotadas pelo Departamento Nacional de Infraestrutura de Transportes (DNIT) (CONCAR, 2010b; DNIT, 2006). Na área de Cartografia, é de grande importância o Decreto $n^{\circ}$ 6.666/2008, que institui no âmbito do poder executivo federal a Infraestrutura Nacional de Dados Espaciais (INDE) (BRASIL, 2008). Entre as normas associadas à CONCAR e à INDE, está a Especificação Técnica de Estruturação de Dados Geoespaciais Vetoriais (ET-EDGV) pelo Comitê Especializado da Mapoteca Nacional Digital (CONCAR, 2010a).

Existem muitos trabalhos sobre a INDE e sobre cadastro territorial, incluindo aspectos de transporte (DAL SANTO, HUBNER e DE OLIVEIRA, 2015; DE SOUSA NETO e CARNEIRO, 2013; DORNELLES e IESCHECK, 2013); entretanto, há poucos trabalhos no Brasil especificamente sobre SRL publicados em periódicos, sendo a maioria teses ou dissertações, relatórios técnicos, ou ainda publicações em anais de eventos (LOPES, 2017; 
MENESES, 2003; CARVALHO, 2002; MOURA et al., 2002; DNIT e UFSC, 2009; FILHO e LOPES, 2018).

No cenário internacional, cada país adota diferentes sistemas, sendo que diversas modelagens conceituais de dados foram propostas ao longo dos anos, comprovando uma preocupação constante na padronização e integração das informações rodoviárias (ADAMS, KONCZ e VONDEROHE, 2001; VONDEROHE e HEPWORTH, 1997; BUTLER, 2008a; DUEKER e BUTLER, 1998; ISAKSSON, 2008). Como consequência desta situação, no ano de 2012 foi publicada a norma internacional 19148 sobre Referenciamento Linear (ISO, 2012a), no âmbito do Comitê Técnico 211 sobre Informação Geográfica e Geomática. Consolidando os conceitos a respeito desta temática, o presente trabalho apresenta uma revisão a respeito das principais definições e modelos de dados para SRL, que possam ser aplicados ao sistema rodoviário e integradas a SIG-T, seguindo as premissas da ISO 19148.

O restante deste artigo está estruturado da seguinte forma: na seção 2 introduzimos brevemente algumas definições básicas de SRL, incluindo Métodos de Referenciamento Linear (MRL). Na seção 3 descrevemos as principais iniciativas nacionais e internacionais, com ênfase nos esforços de padronização. Na seção 4 explicamos os fundamentos da normativa internacional ISO 19148, incluindo o seu diagrama de classes principal e ilustrando vários exemplos de métodos. Já na seção 5 é apresentado um estudo de caso preliminar, no âmbito de um Departamento Estadual de Estradas. Por fim, apresentamos algumas considerações finais e sugestões de trabalhos futuros.

\section{Conceituação Teórica}

Os departamentos de transportes utilizam dados espaciais para localizar ou descrever eventos em um sistema de transportes. Qualquer feição ou evento de transporte pode estar associado a um ou mais dados de referência espacial, de dimensão linear (1D) ou superior (2D ou 3D), e um ou 
mais métodos de medição (por exemplo, fotogrametria ou GPS). As feições ou eventos estão associados a diferentes ordens de medida, isto é, medidas diretamente de acordo com os parâmetros do sistema ou medidas em relação a um ou mais elementos de referência (FEKPE et al., 2003).

Conforme Butler (2008b), a maioria dos departamentos de transportes ao estruturarem seus bancos de dados combinam um conjunto de dados de feições (estradas físicas sendo representadas pela linha central) com uma coleção de tabelas que armazenam vários atributos. Nesta abordagem mista, que integra SRL e SIG, as camadas temáticas (eventos pontuais e lineares) são armazenadas como tabelas e usadas para gerar feições temáticas conforme a necessidade através da segmentação dinâmica. Para tanto, a transformação de dados entre os diferentes sistemas de referência espacial é o aspecto central para a interoperabilidade dos conjuntos de dados (ARCO, 2018; BUTLER, 2008a; FEKPE et al., 2003).

O termo referenciamento linear surgiu a partir de aplicações de engenharia onde era preferível localizar um ponto ao longo de uma feição linear (estradas), fazendo referência a algum outro local bem definido ao invés de usar os sistemas de coordenadas geográficas clássicos. A determinação da localização através de referenciamento linear difere dos tradicionais sistemas de referência geodésicos e cartográficos porque a entidade de base utilizada para a medição não é o elipsoide terrestre, mas sim uma feição linear ou um conjunto de feições lineares organizadas em uma rede (CURTIN, NICOARA e ARIFIN, 2007)

Pode-se destacar a utilização comum de três elementos básicos para o referenciamento linear das informações: a identificação de um ponto conhecido (sendo marcos de referência, placas de sinalização, interseções, etc.); uma direção (por exemplo, da cidade A até a cidade B); e uma medida a partir do ponto de referência.

A ampla utilização de SIG-T e a necessidade da sua integração com os SRL (unidimensionais) previamente existentes nos departamentos de transportes tem provocado uma mistura nos conceitos adotados, causando 
certa confusão na literatura com relação aos termos e seus significados na área de referenciamento linear. A sigla em inglês LRS muitas vezes está se referindo a Linear Referencing System - Sistema de Referenciamento Linear e em outras a Location Referencing System - Sistema de Referenciamento da Localização. O significado destes termos difere dependendo do contexto e autor, porém pode-se generalizar que o primeiro esteja associado ao referenciamento da localização realizada especificamente sobre uma feição linear (unidimensional) e o segundo seja relacionado a um sistema mais amplo com outros tipos de referência da localização (como exemplo, por coordenadas geodésicas). Aqui adotaremos o primeiro significado.

A normativa internacional ISO 19148 define SRL como um conjunto de Métodos de Referenciamento Linear (MRL) e as políticas, registros e procedimentos para a sua aplicação (ISO, 2012a). Já FHWA (2014b) descreve SRL como sendo um método para armazenar e gerenciar informações geoespaciais ao longo de um elemento linear, com posição definida por uma medida de distância ao longo dessa feição linear.

Lewis (2000, p. 97) afirma que $70 \%$ dos dados de um departamento de transportes (por exemplo, pontes, acidentes, etc.) estão vinculados a uma localização geoespacial. De fato, a importância da espacialização das informações de transporte é atestada em trabalhos posteriores, como Butler (2008) e FHWA (2014b). Lewis afirma ainda que SRL é a principal maneira de identificar a localização desses dados e que a localização é o elemento crucial para a integração desses dados. O autor complementa que o SRL está baseado em um deslocamento unidimensional em uma rede predefinida, salientando que, em princípio, é um dos casos mais simples, ainda que na prática possa ser espacialmente e analiticamente complexo.

Para Butler (2008b), um SRL é essencialmente um sistema de coordenadas unidimensional, que usa a distância cumulativa de um ponto de origem para identificar a localização de um ponto na instalação. Cada instalação, portanto, torna-se seu próprio datum para indicar uma localização ao longo de seu comprimento. Ele afirma que a referência linear oferece a 
solução definitiva para restringir o número de classes de feições como uma estratégia para reduzir a carga de trabalho de manutenção e melhorar o desempenho do banco de dados geográficos.

Por mais amplos que sejam os conceitos adotados nesta temática, podese adotar o esclarecimento dado por FHWA (2014b), de que um SRL abrange normalmente vários MRL, além dos procedimentos de escritório e de campo necessários para estabelecer, manter e usar cada método. Também inclui o conhecimento, as habilidades, experiência e tecnologia envolvida com SRL, englobando a totalidade das questões de localização em todas as dimensões usadas dentro de um departamento de transportes.

MRL, para FHWA (2014b), é a maneira como as localizações são medidas ao longo de feições lineares tais como estradas, ferrovias e rotas de ônibus. Com definições variadas ao longo do tempo, o termo MRL pode referirse às medições de campo usando vários tipos de instrumentos (por exemplo, distanciômetros, odômetros, trenas de roda) e também se referir a medições calculadas ao longo das feições lineares cartográficas (por exemplo, polilinhas e curvas), usando algoritmos geoespaciais geométricos (FHWA, 2014b).

\section{Principais Iniciativas}

A grande dificuldade existente no entendimento de SRL está relacionada com a modelagem de dados. O desafio por décadas tem sido desenvolver práticas e modelos de dados genéricos para SRL que sejam adaptáveis, flexíveis e personalizáveis para atender a diferentes ambientes. Frente a isto, diversos projetos e esforços significativos foram desenvolvidos, alguns mais sucedidos do que outros, mesmo considerando que abordagens teóricas para SRL não são muitas vezes práticas para aplicações do mundo real. SRL e modelos de dados associados podem ser complexos, e não existem muitos especialistas na comunidade profissional de SIG-T no desenvolvimento e implementação de SRL (KIEL, 2016). 


\subsection{Cenário internacional}

Entre os diversos modelos propostos para SRL, destacam-se inicialmente os seguintes. Dueker e Butler (1998) apresentam um modelo de dados corporativo de SIG-T incluindo os elementos de SRL. Demirel (2002) apresenta um modelo de dados conceitual para referenciamento da localização multidimensional (envolvendo a geometria 3D e o tempo), considerando uma lista de critérios compilados com base em estudos realizados em sistemas implementados. Vonderohe e Hepworth (1997) apresentam uma metodologia para a concepção de SRL a partir dos princípios e técnicas de engenharia geodésica, na lei de propagação de erros aleatórios e na análise estatística de sistemas de medições redundantes.

Os desenvolvimentos internacionais culminaram na ISO 19148 Informação Geográfica - Referenciamento Linear, uma normativa elaborada sob os auspícios da ISO (International Organization for Standardization Organização Internacional para Normalização). A ISO 19148 expande a parte de SRL da normativa anterior ISO 19133:2005 (ISO, 2005), tanto em funcionalidade quanto em explicações (SCARPONCINI, 2005). Essa normativa utilizou como referência o trabalho desenvolvido por Scarponcini (2002), o qual propôs uma simplificação do modelo NCHRP 20-27 (2). Por sua vez, o NCHRP 20-27 (2) foi desenvolvido no período de 1990 a 2001 (ADAMS, KONCZ e VONDEROHE, 2001) pelo NCHRP (National Cooperative Highway Research Program - Programa Nacional Cooperativo de Pesquisas Rodoviárias), do NRC (National Research Council - Conselho de Pesquisas em Transportes) dos EUA. Scarponcini (2002) propôs um modelo generalizado para referenciamento linear categorizando os Métodos de Referenciamento Linear existentes em um conjunto básico de conceitos comuns e padronizando a localização referenciada linearmente através de uma expressão de posição com três componentes: o Elemento Linear, o Método de Referenciamento Linear e a Expressão de Distância (ISO, 2012a). 
Mais recentemente, cabe destacar o programa conhecido como ARNOLD (All Road Network of Linear Referenced Data - Dados Referenciados Linearmente de Toda a Rede Rodoviária), que é um programa desenvolvido pela FHWA (Federal Highway Administration - Agência Federal de Administração Rodoviária) do USDOT (United States Department of Transportation - Departamento de Transportes dos EUA). Desde 2014 o USDOT vem exigindo que os departamentos estaduais de transporte dos EUA atendam aos novos requisitos dos relatórios HPMS (Highway Performance Monitoring System - Sistema de Monitoramento de Desempenho Rodoviário) (FHWA, 2014a). O produto final previsto no ARNOLD é uma rede de estradas que suporte tanto funções de roteamento como de referenciamento linear. Esta rede deve combinar a geometria da estrada com a topologia da rede, a fim de satisfazer as necessidades de roteamento/navegação e de SRL. As redes rodoviárias resultantes do ARNOLD devem ajudar o USDOT a satisfazer os seus requisitos internos para apoiar programas como o HSIP (Highway Safety Improvement Program -Programa de Melhoria da Segurança Rodoviária) e o NBI (National Bridge Inventory - Inventário Nacional de Pontes), bem como as suas responsabilidades para com outras agências federais (FHWA, 2014b).

Outra entidade de destaque é o OGC (Open Geospatial Consortium Consórcio Geoespacial Aberto), que oferece a especificação para codificação da GML (Geography Markup Language - Linguagem de Marcação Geográfica) (Geography Markup Language; OGC, 2007). A GML baseia-se na XML (eXtensible Markup Language - Linguagem de Marcação extensível) para expressar feições geográficas e serve como uma linguagem de modelagem para sistemas geográficos, bem como um formato de intercâmbio aberto para transações geográficas na Internet. Usando esquemas GML de aplicação, os usuários podem se referir a estradas, rodovias e pontes em vez de pontos, linhas e polígonos. Se todos em uma comunidade concordarem em usar os mesmos esquemas, os envolvidos podem trocar dados facilmente e ter certeza de que uma estrada ainda é uma estrada, como pretendido (OGC, [s.d.]) 
Com relação a SRL, a especificação GML versão 3.3.0 (OGC, 2012b) amplia os esquemas previstos na versão 3.2.1 (OGC, 2007), apresentando esquemas específicos para SRL com base na normativa ISO 19148 (ISO, 2012a). Isso torna possível o uso de GML para intercâmbio de dados de SRL. Cabe ressaltar que a ISO 19148 é adotada pela OGC como padrão próprio OGC 10-030 (OGC, 2012a), porém não é disponibilizada publicamente pois trata-se de especificação desenvolvida em conjunto com a ISO (SIMMONS, 2016). Também em comunicação pessoal com a OGC, através de Simmons (2016), obteve-se a informação de que até aquele momento nenhum software implementava suporte às extensões GML para SRL.

Já a recente especificação LandInfra (Land and Infrastructure Conceptual Model Standard - Modelo Conceitual Padrão para Terras e Infraestrutura) versão 1.0 (OGC, 2016) apresenta uma proposta de modelo conceitual para os setores de infraestrutura e territorial. Este padrão tem conceitos independentes de implementação que suportam infraestrutura de engenharia civil e desenvolvimento territorial e utiliza o SRL previsto na normativa ISO 19148 (ISO, 2012a). Prevê-se que os futuros padrões da OGC relacionados à LandInfra implementarão esses conceitos em várias linguagens, como a GML. Essa norma interage com a normativa de cadastro territorial (ISO, 2012b) no que diz respeito à faixas de domínio, por exemplo.

A temática de sistemas de localização existentes em departamentos de transportes e sua adequação às exigências e normativas atuais tem sido abordada também em pesquisas sobre transportes e segurança viária (ARCO, 2018; OMINSKI, 2018; SIMPSON, 2016; GRAETTINGER et al., 2013, 2009; HALLMARK et al., 2003; KIEL et al., 1999).

\subsection{Cenário nacional}

No Brasil, até o presente momento, não existem normativas específicas para SRL. Porém, existem especificações e normativas das áreas de 
Cartografia e de Transportes que possuem relação com a temática desenvolvida neste trabalho, conforme discutido em seguida.

\subsubsection{Cartografia}

Conforme CONCAR (2010b), a ET-EDGV tem como objetivo a padronização de estruturas de dados de forma a viabilizar o compartilhamento de dados, a interoperabilidade e a racionalização de recursos entre os produtores e usuários de dados e informação cartográfica. A ET-EDGV foi desenvolvida empregando a OMT-G (Object Modeling Technique for Geographic Applications - Técnica de Modelagem de dados orientada a Objetos para Aplicações Geográficas). Atualmente, a norma homologada pela CONCAR é a ET-EDGV versão 2.1.3.

A categoria de informação prevista na ET-EDGV de interesse à presente pesquisa é a de Sistema de Transportes, que por definição de CONCAR (2010b) agrupa o conjunto de sistemas destinados ao transporte e deslocamento de carga e passageiros, bem como as estruturas de suporte ligadas a estas atividades. O diagrama de classe do subsistema rodoviário da ET-EDGV versão 2.1.3 prevê a criação de uma rede rodoviária envolvendo trechos e pontos:

a) Trecho Rodoviário: definida como sendo as ligações rodoviárias entre dois pontos rodoviários, com primitiva geométrica do tipo linha e os seguintes atributos alfanuméricos: código do trecho rodoviário, tipo do trecho rodoviário, jurisdição, administração, concessionária, revestimento, situação operacional, situação física, tráfego; booleanos: geometria aproximada em relação a escala prevista, canteiro divisório; do numéricos inteiros: número de pistas, número de faixas e real: capacidade de carga;

b) Ponto Rodoviário: conexão entre trechos rodoviários, com primitiva geométrica do tipo ponto e dois atributos: geometria aproximada 
em relação a escala prevista (booleano) e indicação do elemento que

o ponto rodoviário está relacionado (alfanumérico).

A ET-EGV não prevê operações relacionadas a SRL, apenas apresenta a estrutura das informações geoespaciais e seus relacionamentos.

\subsubsection{Transportes}

A criação da INDE e as diversas exigências previstas aos dados/informações gerados pelos órgãos públicos federais tem impulsionado recentes ações no setor de transportes. Como principal ação pode-se citar a iniciativa do Plano Estratégico de Geoinformações do Sistema Transportes (PEGEO), programa coordenado pelo Ministério dos Transportes, incluindo a estruturação da Infraestrutura de Dados Espaciais do Setor de Transportes (IDE-T) (MINISTÉRIO DOS TRANSPORTES, 2013， 2015， 2016; MINISTÉRIO DOS TRANSPORTES, PORTOS E AVIAÇÃO CIVIL, 2016). Tem como objetivo integrar tecnologias e políticas capazes de otimizar a produção, armazenamento, acesso, compartilhamento e disseminação de dados geoespaciais, no setor transportes. Conforme Oliveira e Queiroz (2015), as principais etapas de implementação do projeto IDE-T são: a modelagem de dados espaciais do setor Transportes, a elaboração de padrão de cadastramento e publicação de metadados e, finalmente, a instalação e configuração do portal da IDE-T.

Esforços nesse sentido também são desenvolvidos no DNIT, mais especificamente pelo seu Setor de Geotecnologias Aplicadas (DNITGeo) (BORGES e FAZAN, 2017; DNIT, 2017). O DNITGeo tem como objetivos elaborar, estruturar e manter a base de dados geográficos do DNIT, incluindo o desenvolvimento e gestão do cadastro georreferenciado do Sistema Federal de Viação, bem como desenvolver a sua própria Infraestrutura de Dados Espaciais (IDE-DNIT), além de outras incumbências (estudos e projetos, faixa de domínio, fiscalização de contratos referentes a dados geoespaciais, mapas multimodais, etc.). Conforme Mateus (2015), o projeto IDE-DNIT é 
desenvolvido pelo apoio da Empresa de Planejamento e Logística S.A., empresa pública vinculada ao Ministério dos Transportes (BRASIL, 2012; EMPRESA DE PLANEJAMENTO E LOGÍSTICA S.A., 2014).

O Sistema Nacional de Viação (SNV) foi constituído pela Lei $\mathrm{n}^{\circ}$ 12.379/2011 (BRASIL, 2011) e é composto pelo Sistema Federal de Viação (SFV) e pelos sistemas de viação dos estados, do Distrito Federal e dos municípios. O SFV é construído por quatro subsistemas: rodoviário, ferroviário, aquaviário e aeroviário. A administração da infraestrutura do SFV, sob a jurisdição do Ministério dos Transportes, é delegada ao DNIT através da Lei Federal n ${ }^{\circ}$ 10.233/2001 (BRASIL, 2001). Entre as diversas atribuições do DNIT na área rodoviária cabe destaque ao estabelecimento de padrões, normas e especificações técnicas para programas e projetos rodoviários como também o desenvolvimento e gestão de cadastro do SNV.

O Sistema Rodoviário Estadual (SRE) relaciona as rodovias divididas por trechos, com dados como: código, descrição do local do trecho, quilômetro inicial e final, extensão (em $\mathrm{km}$ ), classe da rodovia, situação física, tipo de revestimento, identificação de trecho coincidente e concessão rodoviária. Este conjunto de informações rodoviárias interdependentes é estabelecido seguindo os padrões definidos através do Roteiro Básico para Sistemas Rodoviários Estaduais (DNIT, 2006).

O SRE constitui no registro legal das rodovias. As rodovias são registradas neste sistema mesmo antes de realmente existirem, em etapas de planejamento e projeto, sendo atualizadas conforme sua construção, operação, conservação e por vezes até a extinção. Assim, estas informações rodoviárias devem embasar todos os processos de sistemas de transportes desenvolvidos pelos departamentos estaduais e também servir de fonte de dados para o cálculo dos coeficientes de participação dos estados e Distrito Federal na arrecadação da Contribuição de Intervenção no Domínio Econômico realizado anualmente pelo DNIT. Para tanto, faz-se necessário que as informações relacionadas a esses processos arrecadatórios, e não somente as previstas pelo DNIT (2006), sejam relacionadas de alguma forma ao SRE. 
A normativa DNIT (2006) não prevê a forma de aquisição das informações, inventário de dados, nem a indicação de um sistema (tipo SRL) que possibilite a integração das informações constantes no SRE com as demais informações de infraestrutura viária tais como: dispositivos de sinalização; drenagem e segurança; obras de arte especiais; acidentes rodoviários, eventuais bloqueios de pista, volume de tráfego, etc.

Com relação à precisão nas medições da malha rodoviária a serem cadastradas no SRE, a normativa DNIT (2006) especifica que as extensões e localizações dos trechos rodoviários devam ser expressas em quilômetros, com resolução numérica de 0,1 km (100 metros). Já os dados relativos às obras e projetos rodoviários devem possuir uma resolução submétrica. A precisão não é especificada, mas fica definida implicitamente pelas resoluções numéricas acima, apesar de estar relacionada com a técnica empregada para aquisição das informações e não apenas ao arredondamento destes valores.

\section{Fundamentos da ISO 19148}

A normativa internacional ISO 19148 de Informação Geográfica Referenciamento Linear (ISO, 2012a) define uma descrição dos dados e operações necessárias para a utilização e apoio ao Referenciamento Linear, isso inclui Sistemas de Referenciamento Linear (SRL), eventos localizados linearmente e segmentos lineares. Tal normativa especifica um esquema conceitual, expresso em termos da UML (Unified Modeling Language Linguagem de Modelagem Unificada), para a localização em relação a objetos unidimensionais, contendo medidas ao longo de tais objetos (opcionalmente, com um deslocamento perpendicular). Tem aplicação nas áreas de transporte, serviços públicos, serviços baseados em localização e outras áreas que necessitem da definição de posições relativas a objetos lineares (ISO, 2012a).

A ISO (2012a) define localização referenciada linearmente (LRL) como sendo a localização (local geográfico identificável) cuja posição é especificada utilizando Referenciamento Linear. Assim, a norma propõe uma especificação 
consistente para descrever LRL, e também permitir a transformação entre os diferentes métodos de referenciamento e/ou elementos lineares. Também especifica como expressões de posição podem ser utilizadas para mostrar informações, que dizem respeito apenas a uma parte de um elemento linear, particularizadas como eventos localizados linearmente (ISO, 2012a).

A Figura 1 apresenta o principal diagrama de classe desta normativa do pacote SRL (traduzida para a língua portuguesa pelos autores) com a expressão de posição decomposta nos três principais componentes: o elemento linear, o método de referenciamento linear e a expressão de distância. A seguir apresenta-se um resumo das principais definições adotadas neste esquema, com exemplos de aplicação.

Figura 1 - Diagrama de classes de Sistema de Referenciamento Linear previsto na ISO 19148

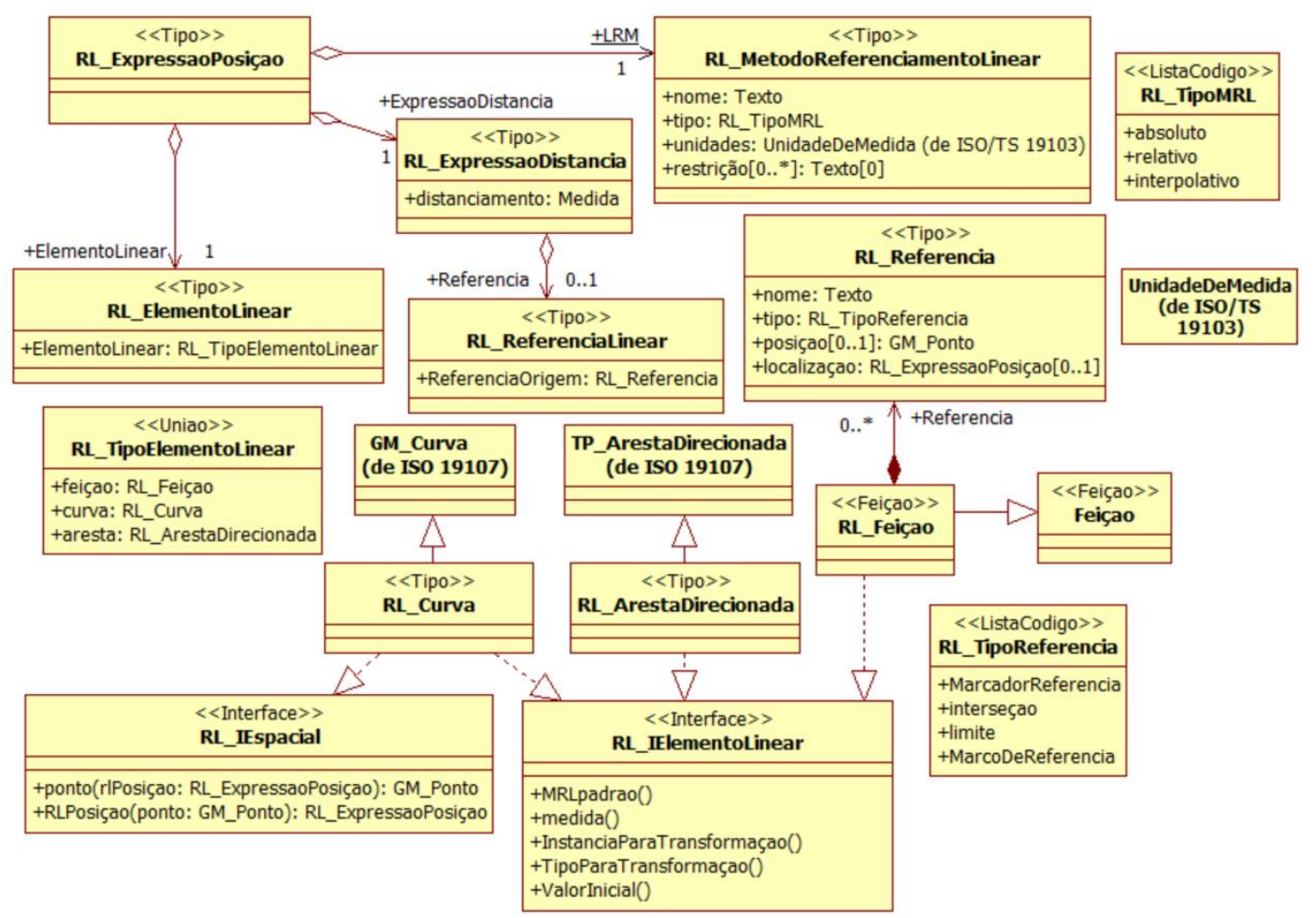

Fonte: Adaptada de ISO (2012a).

Elemento linear (EL) é o termo geral que abrange tudo o que pode ser medido utilizando referenciamento linear. Isto inclui feições previstas a série 
de normativas ISO 191nn, geometrias e topologias lineares. Como exemplo na aplicação rodoviária a rodovia é um EL.

O método de referenciamento linear (MRL) é a forma e unidade de medida em que as medições são realizadas ao longo de um elemento linear. Existem inúmeros MRL em uso hoje, porém a normativa agrupa estes métodos em três tipos: absolutos, relativos e interpolativos.

Em MRL absolutos a medição de distância é realizada a partir do início do elemento linear em uma única direção, utilizando uma determinada unidade de medida, podendo ser milhas (milhagem), quilômetros (quilometragem), metros (metragem) ou múltiplos de $100 \mathrm{~m}$ (hectometragem), como o caso dos mais comuns.

A Figura 2 apresenta um exemplo de como um mesmo evento pode ser expresso através de vários diferentes MRL absolutos. No caso da ocorrência de um acidente rodoviário próximo ao eixo central de uma rodovia, ERS-440, com extensão total aproximada de $9 \mathrm{~km}$. Para o mesmo local, ao utilizar um MRL de milhagem o valor da distância, medida a partir do início da rodovia seria de 2,8 mi, já caso se adote um MRL de quilometragem o valor de distância medida, novamente a partir do início da rodovia, seria de 4,5 km.

Figura 2 - Exemplo 1 de métodos de referenciamento linear absolutos

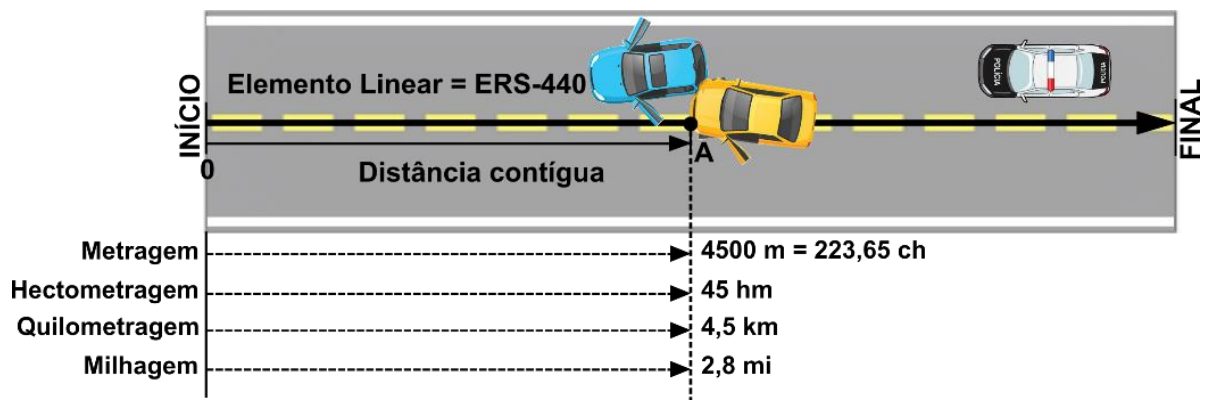

Fonte: Adaptada de Scarponcini (2002) e ISO (2012a).

Em MRL relativos, a medição de distância é realizada a partir de um ponto de referência conhecido sendo que este ponto não precisa estar no início do elemento linear. Os principais tipos são: marco de milhagem, marco de 
quilometragem, marco de referência, milhagem na região, cruzamento e seção de controle.

A Figura 3 apresenta outro exemplo formulado a partir da mesma ocorrência descrita na Figura 2. Para expressar este evento através dos MRL relativos supracitados deve-se utilizar os marcos de referências mais próximos, antecedentes, ao acidente. Assim, para o mesmo local, ao utilizar um MRL por marco de quilometragem, o valor da distância medida em quilômetros ao longo da rodovia a partir do marco quilométrico 4 até o local do acidente seria de $0,5 \mathrm{~km}$ e com isto chega-se ao valor de $4 \mathrm{~km}+0,5 \mathrm{~km}$ para o local do acidente. Da mesma forma no MRL de marco de milhagem é utilizado o de número 2 , sendo a distância medida deste marco até o local do acidente com o valor de 0,8 mi. Com isto, chega-se à expressão de $2 \mathrm{mi}+0,8 \mathrm{mi}$ para o local do acidente. Para um MRL por marco de referência, primeiramente estima-se a localização do marco de referência mais próximo do evento. Neste caso, é o de número 2. Através de um MRL absoluto de milhagem, a distância a partir do início da rodovia até o marco é de $2,3 \mathrm{mi}$; após, realiza-se a medida a partir deste marco de referência, chegando-se ao valor de 0,5 mi. Por fim, pode-se expressar a ocorrência como sendo em $2 \mathrm{mi}$ $+0,5 \mathrm{mi}$ ao longo do elemento linear pelo MRL de marco de referência.

Figura 3 - Exemplo 2 de métodos de referenciamento linear relativos

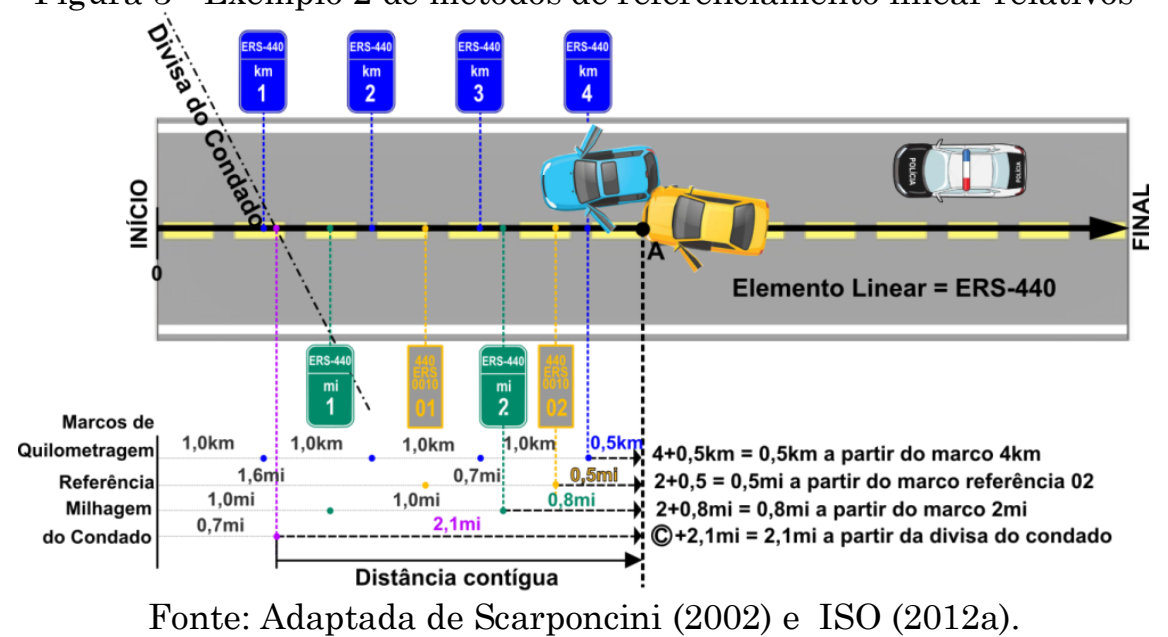


Em MRL interpolativos a distância é medida como uma fração do comprimento total do elemento linear. Como principais tipos pode-se citar porcentagem e o tipo normalizado ou fracionário. Como exemplo destes métodos a partir da mesma ocorrência dos exemplos anteriores para a utilização de um MRL interpolativo de porcentagem a distância medida a partir do início do elemento linear até o acidente (já determinado no exemplo 1) é de $4,5 \mathrm{~km}$, o que equivale ao valor de $50 \%$ da extensão total da rodovia $(9 \mathrm{~km})$. Assim, pelo MRL interpolativo de porcentagem, apresenta um valor de $50 \%$ para o local do acidente e por um MRL interpolativo normalizado este valor equivale a 0,5 (sem unidades).

Figura 4 - Exemplo 3 de métodos de referenciamento linear interpolativos

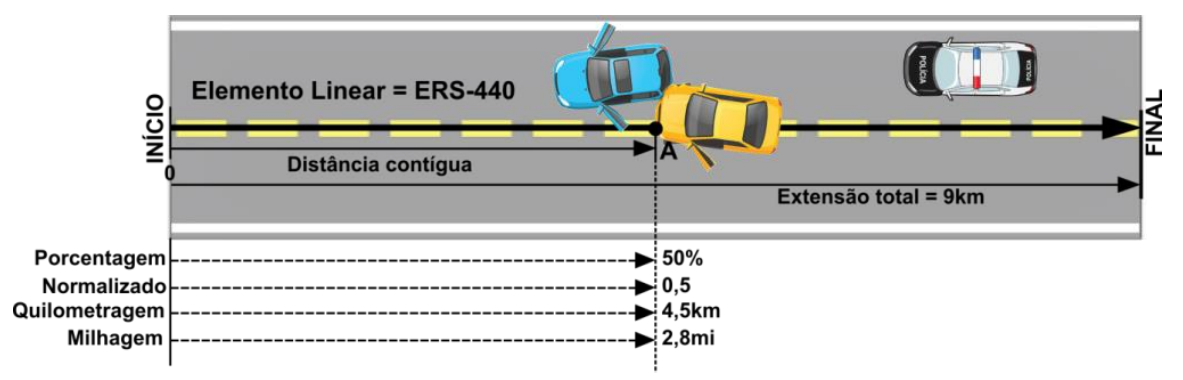

Fonte: Adaptada de Scarponcini (2002) e ISO (2012a).

A expressão de distância é o valor de distância medido ao longo do elemento linear de acordo com um MRL que define a localização de um evento. Os componentes da expressão distância e como se aplicam são dependentes do MRL Linear adotado.

Scarponcini (2002) esclarece que uma expressão de distância deve ser definida como a distância medida ao longo de um elemento linear a partir de algum ponto de partida para a determinação da localização de um evento. A escolha do MRL determina a sintaxe e a semântica dessa expressão. Seguindo o enfoque de Scarponcini (2002), a Tabela 1 a seguir apresenta um resumo das expressões de distância e os MRL adotados no evento exemplificado anteriormente (exemplos 1 a 3). Embora significativamente diferentes em sua 
aparência, significado e precisão, todas as dez expressões de distância definem o mesmo local para o acidente rodoviário.

Tabela 1 - Resumo dos MRL e expressões de distância exemplificadas

\begin{tabular}{c|c|c}
\hline Número & Método de referenciamento linear & Expressão de distância \\
\hline 1 & metragem & $4500 \mathrm{~m}$ \\
\hline 2 & hectometragem & $45 \mathrm{hm}$ \\
\hline 3 & quilometragem & $4,5 \mathrm{~km}$ \\
\hline 4 & milhagem & $2,8 \mathrm{mi}$ \\
\hline 5 & marcos de quilometragem & $4 \mathrm{~km}+0,5 \mathrm{~km}$ \\
\hline 6 & marcos de referência & $2+0,5 \mathrm{mi}$ \\
\hline 7 & marcos de milhagem & $2 \mathrm{mi}+0,8 \mathrm{mi}$ \\
\hline 8 & milhagem na região (condado) & $C+2,1 \mathrm{mi}$ \\
\hline 9 & porcentagem & $50 \%$ \\
\hline 10 & normalizado & 0,5
\end{tabular}

Fonte: Elaborada pelos autores.

A expressão de localização proposta por Scarponcini (2002) é denominada na normativa ISO 19148 como "expressão de posição" (para consistência com a ISO 19133:2005 (ISO, 2005), que trata de um método formal para descrever a localização de um evento. Como pode ser visto através da Tabela 1, os valores das expressões de distância são insuficientes para definir uma LRL. A expressão de posição fornece o contexto para a expressão de distância, incluindo o MRL utilizado, bem como o elemento linear ao longo do qual a distância é medida:

$$
\lambda=(\mu, \varepsilon, \delta)
$$

onde $\lambda$ é uma expressão de posição composta por um MRL $(\mu)$, um elemento linear $(\varepsilon)$, e uma expressão de distância $(\delta)$ cuja sintaxe e a semântica são indicados por $(\mu)$. A normativa ISO 19148 introduz ainda a inclusão de um quarto parâmetro opcional: um valor adicional de deslocamento medido perpendicularmente ao objeto linear.

O Quadro 1 apresenta como podem ser as expressões de posição para as 10 expressões de distância fornecidas na Tabela 1, que especificam o mesmo local do evento (acidente rodoviário), seguindo Scarponcini (2002). 


\begin{tabular}{|c|} 
Quadro 1 - Expressões de Posição exemplificadas \\
\begin{tabular}{|c|} 
Expressão de posição \\
\hline$\lambda 1=$ (metragem, Rota: ERS-440, 4500) \\
\hline$\lambda 2=$ (hectometragem, Rota: ERS-440, 45) \\
\hline$\lambda 3=$ (quilometragem, Rota: ERS-440, 4,5) \\
\hline$\lambda 4=$ (milhagem, Rota: ERS-440, 2,8$)$ \\
\hline$\lambda 5=$ (marcos de quilometragem, Rota: ERS-440, $4+0,5)$ \\
\hline$\lambda 6=$ (marcos de referência, Rota: ERS-440, $2+0,5)$ \\
\hline$\lambda 7=($ marcos de milhagem, Rota: ERS-440, $2+0,8)$ \\
\hline$\lambda 8=($ milhagem na região (condado), Rota: ERS-440, $\odot+2,1)$ \\
\hline$\lambda 9=$ (porcentagem, Link: Link 818,50$)$ \\
\hline$\lambda 10=$ (normalizado, Link: Link $818,0,5)$ \\
\hline Fonte: Elaborado pelos autores.
\end{tabular}
\end{tabular}

\section{Estudo de caso potencial: DAER-RS}

Um estudo de caso preliminar foi desenvolvido junto ao Departamento Autônomo de Estradas de Rodagem do Rio Grande do Sul (DAER-RS) com objetivo de auxiliar na identificação das práticas de cadastro de rodovias adotadas no estado.

O DAER-RS foi criado pela lei estadual n ${ }^{0}$ 750/1937 (RIO GRANDE DO SUL, 1937), como autarquia estadual responsável pela gestão do transporte rodoviário do RS. Em sua regulamentação mais recente, dada pelo Decreto ${ }^{\circ}$ 47.199/2010 (RIO GRANDE DO SUL, 2010), o DAER-RS é vinculado à Secretaria de Transportes e é dotado de personalidade jurídica de direito público.

O conhecimento da malha rodoviária do Rio Grande do Sul é assunto de fundamental importância para que o DAER-RS consiga desempenhar as suas atividades. Para tanto, levantamentos cadastrais foram realizados ao longo dos anos seguindo as premissas definidas pelo DNIT. Entre os principais levantamentos, procedimentos e documentos elaborados, relacionados ao cadastro rodoviário no RS pode-se destacar: a Revisão do Plano Geral Rodoviário (PGR) de 1958 (Departamento Autônomo de Estradas de Rodagem [DAER], 1959); a atualização do PGR do RS de 1975 (DAER, 
1975); o Inventário Final e Completo das Rodovias Pavimentadas pelo DAER (DAER, 1977); a Revisão Antecipada do SRE do RS publicada em 1990 (DAER, 1990); a materialização em campo das divisões dos trechos da rede rodoviária estadual e levantamento odométrico realizado em 1998 (DAER, 1998); em 2003 a aquisição da primeira base vetorial digital através de um levantamento cinemático com GPS de navegação na malha rodoviária, federal e estadual de administração do DAER-RS (DAER, 2003b) e a Revisão Antecipada do SRE do RS de 2006 (DAER, 2006),

Outros levantamentos com propósitos distintos que não a medição da malha rodoviária foram realizados por diversos setores do DAER-RS tais como: Histórico dos Pavimentos da Malha Rodoviária do Rio Grande do Sul em 2003 (DAER, 2003a); Inventário de Obras de Arte Especiais de 2004 a 2007 (DAER, 2007); Levantamento Pavesys - $1^{\circ}$ Ciclo de 2013 e $2^{\circ}$ Ciclo de 2015 (DAER, 2016).

Atualmente o SRE-RS conta com o cadastro de uma malha rodoviária com extensão total de $17.301,55 \mathrm{~km}$, sendo que, destes, $11.528,48 \mathrm{~km}$ apresentam a circunscrição Estadual, composição de Julho/2018 conforme DAER (2018). A Equipe de Cadastro da Superintendência de Programação Rodoviária do DAER-RS é o setor responsável pela implementação do SRERS e também do desenvolvimento de atividades relacionadas à Cartografia, como a elaboração do Mapa Rodoviário do RS e do Mapa Interativo Rodoviário do RS (DRUZINA, 2015).

O cadastro do SRE-RS tem sua atualização não só a partir dos dados derivados de levantamentos em campo, como também através de diversos processos administrativos que tramitam no DAER-RS e que implicam direta ou indiretamente em alterações na malha, tais como: processos de municipalização, estadualização ou federalização de rodovias; regularização/atualização no cadastro de diferentes informações, etc.

Para o armazenamento e gerenciamento dos dados cadastrais do SRERS existem dois principais bancos de dados: o Banco de Dados Convencional (BDC) e o Banco de Dados Geográfico (BDGEO). O BDC está disponível na 
rede interna do DAER-RS e foi elaborado a partir de um Sistema Gerenciador de Banco de Dados (SGBD) proprietário denominado Genexus, apresentando formulários e relatórios com as informações exigidas por DNIT (2006), atributos relacionados à administração do DAER e também um cadastro de Obras de Arte Especiais (OAEs) com informações mínimas derivadas de DAER (2007), que são atualizados regularmente.

O BDC foi concebido utilizando alguns conceitos de SRL, com as informações cadastradas por MRL Absolutos de Quilometragem e Relativos de Marco de Quilometragem. Porém, diversas deficiências neste banco de dados foram constatadas, as quais o distanciam do previsto na normativa ISO 19148, tais como: a maior parte das informações devem ser atualizadas manualmente, sem funções de propagação automática; não permite importação e exportação de dados em formato tabular; não permite o armazenamento da geometria dos traçados, ou seja, não possui módulo geoespacial; o design de relatórios é muito restrito.

A partir de 2013, com o desenvolvimento do projeto Mapa Rodoviário Interativo do RS (DRUZINA, 2015), foi iniciada a implementação do BDGEO, utilizando-se o SGBD PostgreSQL com seu módulo espacial (PostGIS), ambos sistemas livres e de código aberto. Eles seguem os padrões estabelecidos na especificação de feições simples para linguagem de consulta estruturada (SFSQL; OGC, 2010). Algumas das informações do SRE-RS existentes no BDC foram associadas como atributos à base vetorial de rodovias, adquirida em 2003, e armazenada no BDGEO. Através do trabalho de segmentação, codificação e validação de dados foi gerada uma classe de dados geoespaciais, do tipo linha, contendo as informações exigidas por DNIT (2006), denominada de "Trechos Rodoviários".

Por ser um sistema muito recente e em desenvolvimento, o BDGEO ainda não apresenta funcionalidades de SRL implementadas de forma explícita. Ainda que eventos de quilometragem estejam cadastrados, o SRL subjacente é implícito e rudimentar. (A intenção de continuidade para a presente pesquisa será no sentido da elaboração de recomendações para a 
implementação mais completa de SRL neste BDGEO de forma a atender as normativas vigentes.) A Figura 5 ilustra o esquema do BDGEO com as principais tabelas de informações do SRE-RS existentes. Em destaque podese observar a adoção do armazenamento da representação geométrica dos trechos rodoviários em tabela independente (SRE.tra_tgeom_rod), relacionada com outra (SRE.tra_tsre_rod) contendo os atributos alfanuméricos da classe através de uma chave estrangeira, de forma a possibilitar o armazenamento de múltiplos traçados para cada trecho rodoviário.

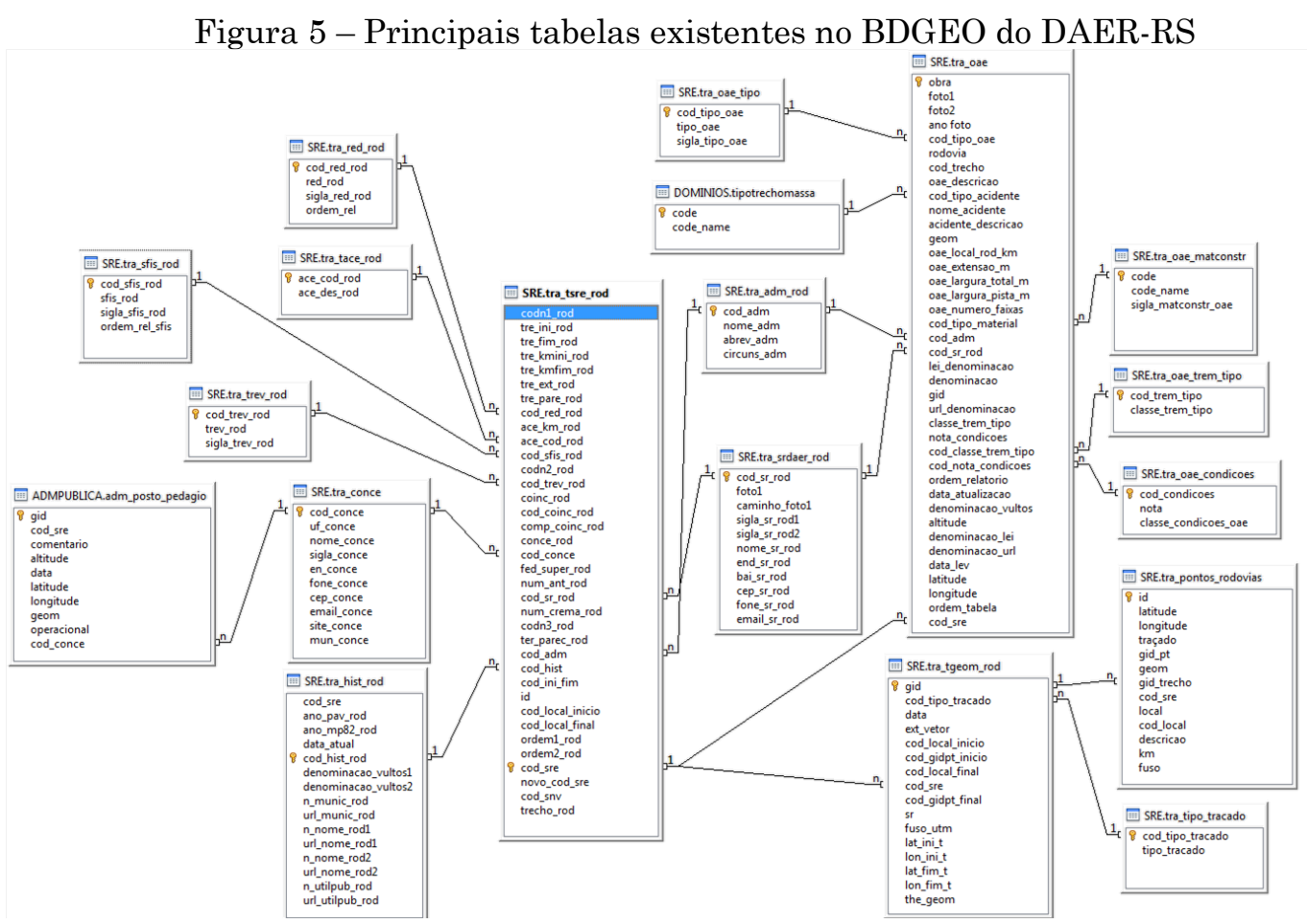

Fonte: Elaborada pelos autores.

Além da elaboração de mapas a partir das informações existentes neste BDGEO, a facilidade operacional impulsionou a elaboração de um novo tipo de relatório do SRE-RS, primeiro em formato tabular, disponibilizado no site do DAER-RS desde 2016, possibilitando uma visão completa e interativa do cadastro de rodovias constante no SRE-RS. 
Em análise, pode-se verificar que a situação atual do cadastro rodoviário do SRE-RS foi determinada principalmente por ocorrências e aspectos técnicos descritos a seguir. A medição da malha rodoviária do RS foi realizada utilizando-se principalmente métodos de levantamento com medição a trena e odômetros de carros. As divisões dos trechos da rede rodoviária foram materializadas em campo em 1998 através da implantação de marcos de concreto amarrados a quilometragem do SRE da época, sem a determinação de coordenadas planimétricas (DAER, 1998). A primeira e única base vetorial digital foi adquirida através de um levantamento cinemático com GPS de navegação realizado em 2003 (DAER, 2003b). Esta base, mesmo apresentando acurácia desconhecida e uma série de problemas topológicos, foi adotada como referência para o cálculo das medidas de extensão de trechos rodoviários, atualizando-se o SRE-RS, com valores expressos em quilômetros e com resolução de 10 metros.

Um grande problema é a falta de definições e especificações nas normativas vigentes com relação a precisão posicional das medições, quanto a forma de aquisição das informações e sistema de integração. A maioria dos dados existentes no DAER-RS ainda estão em formato analógico (em papel), tais como cartas topográficas, projetos de engenharia, diversos mapas históricos, croquis, fotografias, etc. Para que estes dados possam ser utilizados em um banco de dados, devem ser realizados procedimentos de digitalização, vetorização, conversão, criação de atributos e padronização.

Paralelo a isto, as demais informações existentes dentro do DAER-RS são gerenciadas pelas diferentes diretorias, superintendências e setores de forma independente. Até o presente momento, não existe uma integração entre os diferentes bancos de dados específicos (ex., Banco de Dados de Gerência de Pavimentos e Banco de Dados de OAE) com os bancos de dados do SRE-RS. Assim, as alterações que são realizadas no SRE-RS não são acompanhadas de forma direta pelos demais sistemas. Os dados geoespaciais têm sido armazenados de forma descentralizada e não padronizada. 


\section{Desafios}

A metodologia para se realizar a integração de dados geoespaciais à superfície terrestre, tanto linearmente quanto planimetricamente, impõe desafios próprios e pode não estar disponível em um único software de geoprocessamento ou de transportes. Mais especificamente na área rodoviária este cenário esbarra em alguns problemas, tais como: administrar uma grande quantidade de informações georreferenciáveis e relacioná-las a dados pré-existentes (históricos), não padronizados nem georreferenciados; o dinamismo dos dados (com alterações posicionais e de atributos) ao longo do tempo; a imprecisão e/ou inexistência de referenciais (marcos de referência) e da representação digital da via física.

É importante esclarecer que um SRL pode existir de forma independente de um SIG. Nesse caso, não é necessário que os marcos de referência estejam georreferenciados (com coordenadas $2 \mathrm{D}$ ou $3 \mathrm{D}$ ). As operações sobre o SRL sem espacialização explícita servem como apoio às atividades de manutenção das rodovias, como pavimentação, por exemplo. Além disso, os elementos de referência a serem utilizados para a realização da medida (distância) do evento não necessariamente precisam ser objetos dedicados, como placas de quilometragem, podendo ser utilizados outros pontos de conveniência tais como interseções entre vias, pontes, etc.

A dificuldade de manutenção de um SRL é um problema percebido como mais institucional do que tecnológico. É um problema que acomete a qualquer sistema de informação, incluindo SIG (LEWIS, 2000, cap. 9; ADAMS, KONCZ e VONDEROHE, 2001; CURTIN, NICOARA e ARIFIN, 2007; GHARAIBEH et al., 2017; YARBROUGH e WISDOM, 2009). Segundo Curtin et al. (2007), os dados precisam de manutenção quando as rodovias são removidas ou tem seu traçado alterado ao longo do tempo; se surgirem dados mais precisos, as rotas podem ser recalibradas. Afirma ainda que a manutenção dos dados é necessária para manter um SRL funcionando. 
Apesar da prevalência e facilidade da localização por meio de coordenadas geográficas devido à maturação de tecnologias de SIG e GPS/ GNSS (Global Navigation Satellite System - Sistema de Navegação Global por Satélite), os SRL permanecem relevantes e em uso em diversas áreas de Departamentos de Estradas, conforme demonstrado pelo programa ARNOLD (FHWA, 2014b). Setores ligados à construção e obras preferem muitas vezes trabalhar com meras planilhas eletrônicas e quilometragens, por serem percebidos como mais convenientes do que softwares de SIG e coordenadas planimétricas. O que ocorre atualmente é a evolução de SRL para melhor integração entre os dados 1D (lineares) e 2D (mapas).

É importante reconhecer a possibilidade de distorções entre um SRL implantado em campo e o respectivo SRL nominal, suposto no escritório. Tal situação é generalizada em departamentos de transportes. Também não é realista supor que recursos serão dispendidos para substituir marcos de quilometragem em campo. A resolução desse tipo discrepância passa fundamentalmente por reconhecer a coexistência de múltiplos SRL. A solução definitiva envolve uma calibração realista com relação às imperfeições de cada SRL. Somente assim será possível relacionar e cruzar os dados coletados por diferentes usuários ao longo das vias de transporte. Cada comunidade de usuário, como Polícia Rodoviária, Engenheiros de Transportes, etc. empregam seus próprios SRL por conveniência, ainda que isolados e potencialmente distorcidos. É improvável a substituição de tais sistemas legados e adoção de um SRL único. O desafio é integrar os dados em SRL díspares.

\section{Considerações finais}

A definição de Sistemas de Referenciamento Linear (SRL) foi expandida ao longo dos anos de forma a contemplar a integração com dados multidimensionais derivados de Sistemas de Informação Geográfica (SIG). 
Porém, como consequência dessa abordagem evolutiva, não foram adotadas, de forma oficial e universal, práticas para SRL.

Entre os diversos projetos desenvolvidos internacionalmente na última década, destaca-se o programa ARNOLD (FHWA, 2014b) por ter como principal objetivo a integração dos dados rodoviários de todos os estados americanos, e possibilidade de expansão aos municípios, utilizando um SRL único e avançado em conjunto com funções de SIG-T de forma padronizada. O acompanhamento do desenvolvimento deste programa possibilitará a visualização da aplicação de conceitos até então meramente teóricos.

No Brasil, os incipientes programas relacionados a estruturação de dados geoespaciais no setor de Transportes, IDE-T e IDE-DNIT, ainda não apresentam propostas concretas para a padronização do cadastro rodoviário nem a indicação da utilização de SRL.

A norma internacional ISO 19148 (ISO, 2012b) se propõe a padronizar os SRL, sendo um caminho consolidado para a integração de dados geoespaciais, desprendendo-se da necessidade da existência da informação de coordenadas geográficas ou geodésicas. Partindo do fato de que a informação da localização de um determinado evento pode ser fornecida através de diferentes formas, esta normativa fornece uma maneira de traduzir tais diferentes descrições de localização através de expressões de posição de SRL. A simplificação na maneira de pensar acerca da descrição da localização como sendo realizada especificamente sobre uma feição linear (unidimensional) facilita o processo de resgate de dados históricos e manutenção de dados vigentes, sem a necessidade de transformações entre referenciais complexos. No entanto, ainda é um documento normativo relativamente recente e a sua aplicação ainda não foi consolidada nos EUA e no Brasil, permanecendo um amplo campo de estudo.

A realidade do cadastro rodoviário do estado do Rio Grande do Sul, abordadas no estudo de caso junto ao DAER-RS, demonstram a grande necessidade pela integração das diversas informações existentes dentro de um órgão rodoviário. A solução para este problema talvez possa estar relacionada 
a aplicação de SRL como previsto na norma internacional ISO 19148. Como trabalhos futuros, há a formulação de uma proposta para um sistema integrado de cadastro rodoviário geoespacial com base nos princípios de SRL, considerando as normativas vigentes. Aspectos avançados, como a atualização temporal decorrente de mudanças no traçado de vias (DEMIREL, 2002), também são sugeridos para pesquisas futuras.

\section{Contribuição dos autores}

O presente artigo é resultado dos estudos desenvolvidos como parte da tese de doutorado de A.G.S.D. com orientação de S.F.S e de F.G.N. Assim, A.G.S.D. contribuiu em todo o processo de elaboração da pesquisa, desde a conceptualização, investigação, metodologia, curadoria de dados e redação (inicial e revisão). S.F.S e F.G.N desempenharam atividades de supervisão, conceptualização e redação (revisão e edição). Todos os autores aprovaram o artigo.

\section{Referências}

ADAMS, T. M.; KONCZ, N. A.; VONDEROHE, A. P. Guidelines for the implementation of multimodal transportation location referencing systems. Washington, D.C, EUA: National Cooperative Highway Research Program, Transportation Research Board, National Research Council, National Academic Press, 2001. 79p.

ARCO, E. Geomatics for Mobility Management - A comprehensive database model for Mobility Management. Tese de doutoramento. Politecnico di Torino, Doctoral Program in Urban and Regional Development, Torino, Italy, 2018. 244p.

BARNARD, H. Surveying in Egypt. In: Encyclopedia of the History of Science, Technology, and Medicine in Non-Western Cultures. Springer, 2008. pp. 2067-2070. 
BORGES, R. DE O.; FAZAN, A. J. A modelagem geográfica para planejamento da infraestrutura de transportes. $1^{\text {a }}$ Semana do Planejamento - DNIT. Brasília, 2017. 35p. Site: <http://www.dnit.gov.br/1a-semana-doplanejamento/11EstudosdecasoGEO.PDF>, acessado em agosto de 2018.

BRASIL. Lei no 10.233 de 5 de Junho de 2001. Dispõe sobre a reestruturação dos transportes aquaviário e terrestre, cria o Conselho Nacional de Integração de Políticas de Transporte, a Agência Nacional de Transportes Terrestres, a Agência Nacional de Transportes Aquaviários e o Departamento Nacional de Infra-Estrutura de Transportes, e dá outras providências. Brasília, Diário Oficial da União, 6 de junho 2001.

BRASIL. Decreto n ${ }^{\circ} 6.666$ de 27 de Novembro de 2008. Institui, no âmbito do Poder Executivo federal, a Infraestrutura Nacional de Dados Espaciais - INDE, e dá outras providências. Brasília, Diário Oficial da União, 28 de novembro de 2008.

BRASIL. Lei nº 12.379 de 6 de Janeiro de 2011. Dispõe sobre o Sistema Nacional de Viação - SNV. Brasília, Diário Oficial da União, 7 de janeiro de 2011.

BRASIL. Lei no 12.743 de 19 de dezembro de 2012. Altera as Leis nos 10.233, de 5 de junho de 2001, e 12.404, de 4 de maio de 2011, para modificar a denominação da Empresa de Transporte Ferroviário de Alta Velocidade S.A. - ETAV para Empresa de Planejamento e Logística S.A. - EPL, e ampliar suas competências; e revoga dispositivo da Lei no 11.772, de 17 de setembro de 2008. Brasília, Diário Oficial da União, 20 de dezembro de 2012.

BUTLER, J. A. Designing Geodatabases for Transportation. $1^{\text {a }}$ ed. Redlands, California, EUA: ESRI Press, 2008a. 594p.

BUTLER, J. A. Chapter 7: Linear Referencing Methods. In: Designing Geodatabases for Transportation. $1^{\text {a }}$ ed. Redlands, California, EUA: ESRI Press, 2008b. pp. 143-160.

CARVALHO, K. R. Integração da base rodoviária georreferenciada - Banco de Dados do DER/MG (Departamento de Estrada de Rodagem de Minas Gerais). Monografia de especialização. Universidade Federal de Minas Gerais, Instituto de Geociências, Departamento de Cartografia, Curso de Especialização em Geociências, Belo Horizonte, 2002. 45p. 
CONCAR, Comissão Nacional de Cartografia. Plano de Ação para Implantação da Infraestrutura Nacional de Dados Espaciais - INDE. Rio de Janeiro: Comitê de Planejamento da Infraestrutura Nacional de Dados Espaciais, 2010a. 205p.

CONCAR, Comissão Nacional de Cartografia. ET-EDGV Versão 2.1.3: Especificação Técnica para a Estruturação de Dados Geoespaciais Vetoriais. 2.1.3 ed. Brasília: Comitê de Estruturação da Mapoteca Nacional Digital, Subcomissão de Dados Espaciais, Diretoria de Serviço Geográfico do Exército Brasileiro, 2010b. 246p.

CURTIN, K. M.; NICOARA, G.; ARIFIN, R. R. A comprehensive process for linear referencing. URISA Journal, vol. 19, n. 2, 2007. pp. 41-50.

DAER, Departamento Autônomo de Estradas de Rodagem. Plano Geral Rodoviário do Estado do Rio Grande do Sul - Revisão de 1958. Porto Alegre: Oficina Gráfica da Livraria do Globo S/A, 1959. 65p.

DAER, Departamento Autônomo de Estradas de Rodagem. Plano Geral Rodoviário do Estado do Rio Grande do Sul - Revisão de 1975. Relatório Técnico, Porto Alegre, 1975. 59p.

DAER, Departamento Autônomo de Estradas de Rodagem. Inventário Final e Completo das Rodovias Pavimentadas pelo DAER. Porto Alegre: Diretoria de Planejamento, Superintendência de Estudos e Projetos, Equipe de Projetos de Pavimentação, 1977. 22p.

DAER, Departamento Autônomo de Estradas de Rodagem. Revisão Antecipada do Sistema Rodoviário do Estado do Rio Grande do Sul. Relatório Técnico, Porto Alegre, 1990. 160p.

DAER, Departamento Autônomo de Estradas de Rodagem. Execução de serviços de levantamento hodométrico e implantação de marcos de referência na malha rodoviária estadual. Relatório Técnico, Etel Estudos Técnicos Ltda, Porto Alegre, 1998.

DAER, Departamento Autônomo de Estradas de Rodagem. Histórico dos pavimentos da malha rodoviária do Rio Grande do Sul. Relatório Técnico, Departamento de Programação Rodoviária, Seção de Cadastro, Porto Alegre, 2003a. 
DAER, Departamento Autônomo de Estradas de Rodagem. Processo Administrativo no 011999-1835/03-1 - Contrato PJ/CD/171/02 - Sistema de planejamento rodoviário integrado. Consórcio Prodec - Transplan Beck de Souza, Porto Alegre, 2003b.

DAER, Departamento Autônomo de Estradas de Rodagem. Revisão Antecipada do Sistema Rodoviário do Estado do Rio Grande do Sul. Relatório Técnico, Departamento de Programação Rodoviária, Seção de Cadastro, Porto Alegre, 2006. pp. 1-39.

DAER, Departamento Autônomo de Estradas de Rodagem. Inventário de Obras de Arte Especiais. Relatório Técnico, Departamento de Programação Rodoviária, Seção de Cadastro, Porto Alegre, 2007.

DAER, Departamento Autônomo de Estradas de Rodagem. Contratos de serviços especializados para levantamentos nas rodovias pavimentadas do DAER. Porto Alegre: Diretoria de Gestão e Projetos, Superintedência de Pesquisas Rodoviárias, 2016.

DAER, Departamento Autônomo de Estradas de Rodagem. Composição da Malha Rodoviária do Rio Grande do Sul de Julho/2018. Site <http://www.daer.rs.gov.br/composicao-da-malha>, acessado em outubro de 2018.

DAL SANTO, M. A.; HUBNER, C. E.; DE OLIVEIRA, F. H. Gestão da Informação Geográfica e Cadastral no Brasil. Revista Brasileira de Cartografia, vol. 67, n. 2, 2015. pp. 215-259.

DE SOUSA NETO, J. A.; CARNEIRO, A. F. T. Modelagem do Cadastro Nacional de Imóveis Rurais-CNIR com vistas à sua integração à Infraestrutura Nacional de Dados Espaciais-INDE. Revista Brasileira de Cartografia, vol. 65, n. 2, 2013. pp. 303-314.

DEMIREL, H. An Integrated Approach to the Conceptual Data Modeling of an Entire Highway Agency Geographic Information System ( GIS ). Tese de doutoramento. Universidade Técnica de Berlim, Faculdade VI Engenharia Civil e Geociências Aplicadas, Berlim, Alemanha, 2002. 131p.

DNIT, Departamento Nacional de Infraestrutura de Transportes. Roteiro Básico para Sistemas Rodoviários Estaduais. $2^{\mathrm{a}}$ ed. Brasília: Instituto de Pesquisas Rodoviárias, 2006. 56p. 
DNIT, Departamento Nacional de Infraestrutura de Transportes. Sobre o DNITGeo. Site <http://www.dnit.gov.br/planejamento-e-pesquisa/dnitgeo/copy_of_dnitgeo>, acessado em agosto de 2018.

DNIT, Departamento Nacional de Infraestrutura de Transportes; UFSC, Universidade Federal de Santa Catarina. Elaboração de um Sistema de Referência Linear para o Plano Nacional de Viação baseado em dados geográficos - SRL-PNV: Elaborar diretrizes técnicas e parâmetros operacionais para que o DNIT executeprojetos de monitoramento de tráfego na Malha Rodoviária Federal. Relatório Técnico, Laboratório de Transportes, Florianópolis 2009. 60p.

DORNELLES, M. A.; IESCHECK, A. L. Análise da aplicabilidade da Infraestrutura Nacional de Dados Espaciais (INDE) para dados vetoriais em escalas grandes. Boletim de Ciências Geodésicas, vol. 19, n. 4, 2013. pp. 667-686.

DRUZINA, A. G. DA S. Mapa Interativo Rodoviário do RS. Revista Estradas, vol. 14, n. 20, 2015. pp. 69-75.

DUEKER, K. J.; BUTLER, J. A. GIS-T enterprise data model with suggested implementation choices. Journal of the Urban and Regional Information Systems Association, vol. 10, n. 1, 1998. pp. 12-36.

EMPRESA DE PLANEJAMENTO E LOGÍSTICA S.A.. Relatório com a metodologia de elaboração da rede georreferenciada multimodal. Relatório Técnico, Brasília, 2014. 40p.

FEKPE, E. et al. NCHRP Report 506 - Quality and accuracy of positional data in transportation. Realtório Técnico, National Cooperative Highway Research Program, Transportation Research Board, National Research Council, National Academic Press, Washington, 2003. 108p.

FHWA, Federal Highway Administration. Highway Performance Monitoring System: Field Manual. Relatório Técnico, Office of Highway Policy Information, Washington, 2014a. 284p.

FHWA, Federal Highway Administration. ARNOLD-All Road Network of Linear Referenced Data: Task 6- Reference Manual. Relatório Técnico, Applied Geographics Inc., Washington, 2014b. 100p.

FILHO, G. G. M. A.; LOPES, S. B. Uso de plataformas livres de Sistemas de Informação Geográfica na Engenharia de Transportes. Anais do $\mathbf{3 2}^{\mathbf{o}}$ 
Congresso de Pesquisa e Ensino em Transporte da ANPET: Modelos e Técnicas de Planejamento de Transporte, Modelos de Otimização em Transportes, Gramado, 2018. pp. 2573-2585.

GHARAIBEH, N. et al. NCHRP - Synthesis of Highway Practice 508: Data Management and Governance Practices - The National Academies Press: National Cooperative Highway Research Program Report - Synthesis of Highway Practice 508, Transportation Research Board, Washington, 2017. $107 \mathrm{p}$.

GRAETTINGER, A. et al. Combining State Route and Local Road Linear Referencing System Information. Transportation Research Record: Journal of the Transportation Research Board, vol. 2121, 2009. pp. 152159.

GRAETTINGER, A. et al. Translating Transportation Data Between Linear Referencing Systems of Dissimilar Resolution. Transportation Research Record: Journal of the Transportation Research Board, vol. 2399, 2013. pp. 103-111.

HALLMARK, S. et al. Integration of spatial point features with linear referencing methods. Transportation Research Record: Journal of the Transportation Research Board, vol. 1836, 2003. pp. 102-110.

ISAKSSON, P. Specifications for Establishing a Road Data Infrastructure. Anais do FIG Working Week 2008: Integrating Generations, Estocolmo, Suécia, 2008. 14p.

ISO, International Organization for Standardization. ISO 19133: Geographic information - Location-based services - Tracking and navigation. Technical Committee 211- Geographic information/Geomatics, 2005.

ISO, International Organization for Standardization. ISO 19148: Geographic information - Linear referencing. Technical Committee 211 - Geographic information/Geomatics, CEN/TC 287 Geographic Information, 2012a.

ISO, International Organization for Standardization. ISO 19152: Geographic information - Land Administration Domain Model (LADM). Technical Committee 211 - Geographic information/Geomatics, 2012b. 
KIEL, D. et al. Linear Referencing System for North Carolina Department of Transportation. Transportation Research Record: Journal of the Transportation Research Board, vol. 1660, 1999, pp. 108-113.

KIEL, D. GEOG 497C Transportation GIS: Lesson 2 - GIS-T Concepts and Linear Referencing Systems. The Pennsylvania State University, College of Earth and Mineral Sciences, John A. Dutton e-Education Institute. Site $<$ https://www.e-education.psu.edu/transportation/print/book/export/html/6>, acessado em julho de 2016.

LEWIS, J. S. Transportation linear referencing toolboxes: a "reflective practitioner's" design approach. Tese de doutoramento. Instituto de Tecnologia de Massachusetts, Cambridge, Massachusetts, EUA, 2000. 500p.

LOCH, C. Cadastro Técnico Multifinalitário: Rural e Urbano. Cambridge, Massachusetts, EUA: Lincoln Institute of Land Policy, 2007. 142p.

LOPES, C. H. R. Considerações sobre a estrutura de dados espaciais de rodovias no Brasil. Dissertação de mestrado. Universidade Federal de Santa Catarina, Programa de Pós-graduação em Engenharia de Transporte e Gestão Territorial, Florianópolis, 2017. 154p.

MATEUS, D. L. S. Infraestrutura de Dados Espaciais (IDE-DNIT). Workshop Observatório Logístico de Transporte. Brasília, 2015. 16p.

MENESES, H. B. Interface Lógica em ambientes SIG para Bases de Dados de Sistemas Centralizados de Controle do Tráfego Urbano em Tempo Real. Dissertação de mestrado. Universidade Federal do Ceará, Programa de Mestrado em Engenharia de Transportes, Fortaleza, 2003. 204p.

MINISTÉRIO DOS TRANSPORTES. Portaria n ${ }^{\circ} 1$ de 30 de outubro de 2013. Institui a iniciativa estratégica responsável pela elaboração e proposição do Plano Estratégico de Geoinformações de Transportes - PEGEO. Diário Oficial da União, 31 de outubro de 2013.

MINISTÉRIO DOS TRANSPORTES. Prestação de contas ordinária anual Relatório de gestão do exercício de 2014. Relatório Técnico, Ministério dos Transportes, Secretaria Executiva, Brasília, 2015. 213p.

MINISTÉRIO DOS TRANSPORTES. Prestação de contas ordinária anual Relatório de gestão do exercício de 2015. Ministério dos Transportes, Secretaria Executiva, Brasília, 2016. 209p. 
MOURA, M. C. DE et al. Criação de Rede e Base de Dados para o Sistema Viário de Viçosa - MG, utilizando SIG. Revista Brasileira de Cartografia, vol. 54, n. 1, 2002. 8p.

MINISTÉRIO DOS TRANSPORTES, PORTOS E AVIAÇÃO CIVIL. Plano Estratégico de Geoinformações de Transportes - PEGEO. Site $<$ http://www.transportes.gov.br/conteudo/52-sistema-de-transportes/3959plano-estrat\%C3\%A9gico-de-geoinforma\%C3\%A7\%C3\%B5es-de-transportes$\% \mathrm{E} 2 \% 80 \% 93$-pegeo.html>, acessado em julho de 2018.

OGC, Open Geospatial Consortium. OGC 07-036: Geography Markup Language (GML) - Encoding Standard, 3.2.1 ed., Clemens Portele, 2007.

OGC, Open Geospatial Consortium. OGC 06-104r4: Implementation Standard for Geographic information - Simple feature access - Part 2: SQL option. 1.2.1 ed. John R. Herring, 2010.

OGC, Open Geospatial Consortium. OGC 10-030: Abstract Specification - Topic 19: Geographic information - Linear referencing (ISO 19148). Paul Scarponcini, 2012a.

OGC, Open Geospatial Consortium. OGC 10-129r1: Geography Markup Language (GML) - Extended schemas and encoding rules. 3.3.0 ed. Clemens Portele, 2012b.

OGC, Open Geospatial Consortium, OGC 15-111r1: Land and Infrastructure Conceptual Model Standard (LandInfra). 1.0 ed., Paul Scarponcini, 2016.

OGC, Open Geospatial Consortium. Geography Markup Language I OGC. Site <http://www.opengeospatial.org/standards/gml>, acessado em maio de 2017.

OLIVEIRA, W. DE L.; QUEIROZ, F. IDE-T Infraestrutura de Dados Espaciais de Transportes. Encontro de usuários ESRI Brasil. Rio de Janeiro, 2015. Site $<$ http://archive.img.com.br/apresentacoes_euesri/trilha_governo_federal/euesr i2015_govfed_a_geoinformacao_no_setor_dos_transportes_min_dos_transport es_wagnerlima_felipequeiroz.pdf>, acessado em maio de 2017.

OMINSKI, A. Development and Attribution of a Linear Referencing System for Managing and Disseminating Traffic Volume Data on Rural Highway Networks. Dissertação de mestrado. University of Manitoba, Department of Civil Engineering, Winnipeg, Manitoba, 2018. 133p. 
PAULSON, J. F. Surveying in Ancient Egypt. From Pharaohs to Geoinformatics FIG Working Week and GSDI-8. Cairo, Egito, 2005. 12p.

RIO GRANDE DO SUL. Lei no 750 de 11 de Agosto de 1937. Cria o Departamento Autônomo de Estradas de Rodagem diretamente subordinada à Secretaria de Estado dos Negócios das Obras Públicas e determina outras providências. Diário Oficial do Estado do Rio Grande do Sul, 11 de agosto de 1937.

RIO GRANDE DO SUL. Decreto no 47.199 de 27 de Abril de 2010. Dispõe sobre o Regulamento do Departamento Autônomo de Estradas e Rodagem - DAER. Diário Oficial do Estado do Rio Grande do Sul, 28 de abril de 2010.

SCARPONCINI, P. Generalized Model for Linear Referencing in Transportation. GeoInformatica, vol. 6, n. 1, 2002, pp. 35-55.

SCARPONCINI, P. ISO 19133 Tracking and Navigation Standard: 6.6 Linear Reference System Standard. Transportation Research Record: Journal of the Transportation Research Board, vol. 1935, 2005, pp. 77-84.

SIMMONS, S. Pedido de acesso a OGC 10-030, Abstract Specification Topic 19: Geographic information - Linear referencing. [mensagem pessoal]. Mensagem recebida por <felipe.nievinski@ufrgs.br> em 11 de agosto de 2016. SIMPSON, M. E. Enhancing the spatial resolution of an active linear referencing system and calibrating a functional merge. Dissertação de mestrado. University of Alabama, Department of Civil, Construction, ando Environmental Engineering, Tuscaloosa, Alabama, 2016. 208p.

VONDEROHE, A.; HEPWORTH, T. A Methodology for Design of a Linear Referencing System for Surface Transportation. Relatório Técnico. SAND 97-0637, Sandia Contract: AT-4567, Sandia National Laboratories, Albuquerque, New Mexico, 1997. 79p.

YARBROUGH, G.; WISDOM, J. NCHRP Project 08-36 -Task 80 - Synthesis of State Practices in Developing Linear Referencing System. Relatório Técnico. American Association of State Highway, Standing Committee on Planning, National Cooperative Highway Research Program, Transportation Research Board, National Research Council, Washington, 2009. 73p. 